\title{
EBSD Characterization of Cryogenically Rolled Type 321 Austenitic Stainless Steel
}

\author{
GALIA KORZNIKOVA, SERGEY MIRONOV, TATYANA KONKOVA, \\ AINUR ALETDINOV, RIDA ZARIPOVA, MIKHAIL MYSHLYAEV, \\ and SHELDON SEMIATIN
}

\begin{abstract}
Electron backscatter diffraction was applied to investigate microstructure evolution during cryogenic rolling of type 321 metastable austenitic stainless steel. As expected, rolling promoted deformation-induced martensitic transformation which developed preferentially in deformation bands. Because a large fraction of the imposed strain was accommodated by deformation banding, grain refinement in the parent austenite phase was minimal. The martensitic transformation was found to follow a general orientation relationship, $\{111\}_{\gamma}\left\|\{0001\}_{\varepsilon}\right\|$ $\{110\}_{\alpha^{\prime}}$ and $\langle 110\rangle_{\gamma}||\langle 11-20\rangle_{\varepsilon} \mid\langle 111\rangle_{\alpha^{\prime}}$, and was characterized by noticeable variant selection.
\end{abstract}

https://doi.org/10.1007/s11661-018-4919-2

(c) The Minerals, Metals \& Materials Society and ASM International 2018

\section{INTRODUCTION}

THE opportunity for substantial enhancement of mechanical properties has given rise to considerable interest in the production of ultrafine-grain microstructures in engineering materials. Typically, this is achieved through the application of severe plastic deformation techniques, ${ }^{[1]}$ but these methods are laborious and difficult to use for the fabrication of commercial-scale quantities. In metastable austenitic stainless steel sheet products, however, substantial grain refinement may be obtained by conventional cold rolling followed by annealing due to the occurrence of a deformation-induced martensitic transformation and the subsequent austenite reversion. ${ }^{[2-17]}$ Among these two processing steps, the deformation

GALIA KORZNIKOVA and AINUR ALETDINOV are with the Institute for Metals Superplasticity Problems, Russian Academy of Science, 39 Khalturin Str., Ufa, Russia, 450001. SERGEY MIRONOV is with the Belgorod National Research University, Pobeda 85, Belgorod, Russia, 308015. Contact e-mail: mironov@bsu.edu.ru TATYANA KONKOVA is with the Institute for Metals Superplasticity Problems, Russian Academy of Science and also with the University of Strathclyde, 75 Montrose Street, Glasgow, G1 1XJ. RIDA ZARIPOVA is with the Ufa State Aviation Technical University, 12 K. Marx St., Ufa, Russia, 450000. MIKHAIL MYSHLYAEV is with the Baikov Institute of Metallurgy and Material Science, Russian Academy of Science, 49 Lenin-av., Moscow, Russia, 119991 and also with the Institute of Solid State Physics, Russian Academy of Sciences, 2 Academic Osypian Str., Chernogolovka, Moscow Oblast, Russia, 142432. SHELDON SEMIATIN is with the Air Force Research Laboratory, Materials and Manufacturing Directorate, AFRL/RXCM, Wright-Patterson AFB, OH 45433-7817.

Manuscript submitted April 13, 2018.

Article published online September 17, 2018 stage appears to be of particular interest because the resulting microstructure essentially determines the final grain refinement effect.

Extensive investigation of the phenomenon of the deformation-induced martensitic transformation over $\sim 50$ years has demonstrated its remarkable complexity. ${ }^{[18]}$ Due to the relatively low stacking fault energy (SFE) of the austenitic steels, plastic straining of such materials is well accepted to be characterized by planar slip, mechanical twinning, and shear banding, ${ }^{[19]}$ features often associated with the dissociation of perfect dislocations into Shockley partials and stacking faults. ${ }^{[20]}$ With increasing dislocation density, the stacking faults may overlap and, depending on the nature of this process, lead to either twinning ${ }^{[21]}$ or the formation of hexagonal-close-packed $\varepsilon$-martensite. ${ }^{[2-27]}$ The $\varepsilon$-martensite is believed to be a transient phase which eventually transforms into body-centered-tetragonal $\alpha^{\prime}$-martensite. ${ }^{[18,28-33]}$ On the other hand, the direct phase transformation $\gamma \rightarrow \alpha^{\prime}$ is also possible. ${ }^{[18,22,28,29,31-37]}$ In this case, the $\alpha^{\prime}$-martensite may nucleate at dislocation pile-ups, ${ }^{[18,22,29,34]}$ mechanical twins, ${ }^{[18,32-37]}$ or deformation bands. ${ }^{[18,28,29,31,32,37]}$ It appears that $\alpha^{\prime}$-martensite results from interactions between dislocations, stacking faults, and/or $\varepsilon$-martensite, but the mechanism is not clear. It has been suggested that the activation of the specific transformation sequence, i.e., $\gamma \rightarrow \varepsilon \rightarrow \alpha^{\prime}$ vs $\gamma \rightarrow \alpha^{\prime}$, is governed by the magnitude of the SFE. Lower energy favors the formation of the $\varepsilon$-phase ${ }^{[32]}$ After nucleation, $\alpha^{\prime}$-martensite is believed to grow rapidly in an autocatalytic manner ${ }^{[18,32]}$ but the details of this process are also not completely clear. The austenitic and martensitic phases are believed to be related through the orientation relationship $\{111\}_{\gamma}||\{0001\}_{\varepsilon} \mid\{110\}_{\alpha^{\prime}}$ and $\langle 110\rangle_{\gamma}||\langle 11-20\rangle_{\varepsilon}$ 
$\|\langle 111\rangle_{\alpha^{\prime}}{ }^{[2,11]}$ although substantial deviations are sometimes reported. ${ }^{[36]}$

The size of the mechanical twins and shear bands as well as the deformation-induced $\varepsilon$ - and $\alpha^{\prime}$-martensite particles is typically found to be $\sim 100 \mathrm{~nm} .^{[30-44]}$ It is believed, therefore, that the occurrence of phase transformation during deformation promotes rapid grain refinement, even at relatively low strains during conventional rolling. ${ }^{[33,36,39-41,43-45]}$ Moreover, it is widely accepted that a reduction in deformation temperature may further enhance the grain-refinement effect. Specifically, lowering the processing temperature should lower the $\mathrm{SFE}^{[31,33,41]}$ and thus promote mechanical twinning and the formation of $\varepsilon$-martensite. The slip/twinning threshold stress ratio should also decrease with temperature, additionally contributing to twinning activity. ${ }^{43]}$ Last, lowering the deformation temperature would tend to increase the driving force for $\alpha^{\prime}$-martensitic transformation. In a view of these benefits, the deformation of austenitic steels at cryogenic temperatures has attracted substantial recent interest. ${ }^{[17,33,39,40,43-45]}$ However, current understanding of deformation-induced martensitic transformation has been based primarily on microstructural observations from transmission electron microscopy. Despite the excellent resolution of this technique, the statistical reliability of such results can be questioned. To overcome this shortcoming, electron backscatter diffraction (EBSD) is becoming increasingly popular for examination of the phenomenon. However, due to the heavily deformed nature of evolving microstructures in such cases, such observations are relatively difficult and thus still limited in extent. Hence, the present research using EBSD with improved spatial resolution was undertaken to provide further insight into the phase transformations and their relationship with grain refinement.

\section{MATERIAL AND EXPERIMENTAL PROCEDURES}

The program material comprised type 321 metastable austenitic stainless steel with nominal*

*According to Russian industrial standard.

chemical composition as shown in Table I. It was rolled to 85 pct thickness reduction at $950{ }^{\circ} \mathrm{C}$ and then annealed at $1200{ }^{\circ} \mathrm{C}$ for 1 hour, thereby producing a fully recrystallized austenitic grain structure with a mean grain size of $\sim 100 \mu \mathrm{m}$, a high fraction of annealing twins, and a weak $\{111\}\langle u v w\rangle \gamma$-fiber texture (Supplementary Figure S-1.**) Microstructural observations by

**Refer to electronic supplementary material.

using backscatter scanning electron microscopy revealed no evidences of large-scale chemical heterogeneity, at least for the TD-RD plane. Therefore, the applied preprocessing was suggested to eliminate the possible segregation of nickel and chromium, although additional observations on the other (orthogonal) planes are necessary to verify this issue. This process produced what is referred to as the starting condition for the research described herein.

The characteristic martensite transformation temperatures as well as stacking fault energy of the starting material were evaluated by using the widely accepted equations (e.g., Reference 17) shown below and the obtained results are summarized in Table II.

$$
\begin{aligned}
M_{\mathrm{s}}= & 1302-42(\text { pct } \mathrm{Cr})-61(\mathrm{pct} \mathrm{Ni})-33(\text { pct Mn }) \\
- & 28(\text { pct Si })-1667(\text { pct } \mathrm{C}+\text { pct N }), \\
\mathrm{Md}_{30 / 50}= & 551-462(\text { pct } C+\text { pct N })-9.2(\text { pct Si }) \\
& -8.1(\text { pct } \mathrm{Mn})-13.7(\text { pct } \mathrm{Cr}) \\
& -29(\text { pct } \mathrm{Cu}+\text { pct Ni })-18.5(\text { pct Mo }) \\
& -68(\text { pct Nb })-1.42(G-8), \\
\mathrm{SFE}= & -53+6.2(\text { pct Ni })+0.7(\text { pct } \mathrm{Cr})+3.2(\text { pct Mn }) \\
+ & 9.3(\text { pct Mo }),
\end{aligned}
$$

where $M_{\mathrm{s}}$ is the martensite start temperature (in ${ }^{\circ} \mathrm{C}$ ); $\mathrm{Md}_{30 / 50}$ is the temperature (in ${ }^{\circ} \mathrm{C}$ ) at which 50 pct of austenite is expected to transform into deformation-induced martensite at 30 pct engineering strain; $G$ is the ASTM grain size number (accepted to be 4 in the present study), and SFE is stacking fault energy (in $\mathrm{mJ} / \mathrm{m}^{2}$ ). In all cases, the alloying elements are quoted in weight percent.

The material was cryogenically rolled to 30 pct overall thickness reduction (true strain $=-0.36){ }^{\dagger}$ The reduc-

${ }^{\dagger}$ The thickness of initial sheet was $2.3 \mathrm{~mm}$.

tion was performed in a single pass using a rolling speed of $160 \mathrm{~mm} / \mathrm{s}$ in a cluster mill with $65-\mathrm{mm}$-diameter work rolls. Higher reductions were found to lead to significant (undesirable) deformation heating and roll-separating forces which exceeded the capacity of the laboratory equipment. To provide cryogenic deformation conditions, the rolling preform was soaked in liquid nitrogen and held for 15 minutes prior to rolling. The total time for the rolling process (i.e., the exposure time of the workpiece under ambient conditions) was only a few seconds. Assuming deformation heating to be a dominant contributor to material warming, the deformation temperature was estimated to be $\sim-100{ }^{\circ} \mathrm{C}$ (Supplementary Material). Immediately after rolling, each specimen retained a frosty appearance, thus suggesting that deformation had occurred under cryogenic (or freezing, at least) conditions. The typical flat-rolling convention was adopted in this work; i.e., the rolling, long-transverse, and thickness/normal directions were denoted as RD, TD, and ND, respectively. 
Table I. Nominal Chemical Composition of Program Material (Weight Percent) According to Russian Industrial Standard

\begin{tabular}{lcccccccccc}
\hline $\mathrm{Fe}$ & $\mathrm{C}$ & $\mathrm{Cr}$ & $\mathrm{Ni}$ & $\mathrm{Mn}$ & $\mathrm{Ti}$ & $\mathrm{Si}$ & $\mathrm{Cu}$ & $\mathrm{S}$ & $\mathrm{P}$ \\
\hline Balance & $\leq 0.12$ & 17 to 19 & 9 to 10 & $\leq 2.0$ & 0.4 to 1.0 & $\leq 0.8$ & $\leq 0.3$ & $\leq 0.02$ & $\leq 0.035$ \\
\hline
\end{tabular}

Table II. Characteristic Martensite Transformation Temperatures and Stacking Fault Energy

\begin{tabular}{ccc}
\hline$M_{\mathrm{s}}\left({ }^{\circ} \mathrm{C}^{*}\right)$ & $M \mathrm{~d}_{30 / 50}\left({ }^{\circ} \mathrm{C}\right)$ & $\mathrm{SFE}\left(\mathrm{mJ} / \mathrm{m}^{2}\right)$ \\
\hline- & -6 & 23.26 \\
\hline
\end{tabular}

To prevent static recovery and thus preserve the deformation-induced microstructure, cryogenically rolled samples were stored in a freezer at $\sim-20{ }^{\circ} \mathrm{C}$ prior to microstructural examination. Microstructural characterization was performed on the mid-thickness rolling plane (i.e., RD-TD plane) using EBSD. For this purpose, samples were prepared using conventional metallographic techniques involving grinding with abrasive papers, diamond polishing, and final electro-polishing in a solution of 95 pct acetic acid +5 pct perchloric acid at near-zero-temperature conditions (i.e., in an ice bath) with an applied potential of $30 \mathrm{~V}$. For EBSD, a JSM-7800F field-emission-gun scanning-electron microscope (FEG-SEM) operating at an accelerating voltage of $25 \mathrm{kV}$ and a TSL OIM ${ }^{\mathrm{TM}}$ system were employed. This SEM provided a relatively large beam current with a small diameter, thus enabling EBSD even for the heavily deformed material.

To examine the microstructure at different length scales, several EBSD maps were acquired. Low-resolution (overview) maps were obtained using a scan step size of $1 \mu \mathrm{m}$; higher-resolution maps were acquired using a scan step size of $50 \mathrm{~nm}$. For each diffraction pattern, nine Kikuchi bands were used to minimize indexing error. The $\alpha^{\prime}$-martensite was indexed as a body-centered-cubic phase; this approach is believed to be feasible for EBSD of steels. ${ }^{[46]}$ Considering the high density of crystal defects as well as the nano-scale characteristics of $\varepsilon$-martensite, detection of this phase is often believed to be challenging. Nevertheless, the feasibility of EBSD for this purpose has been demonstrated in a number of recent efforts (e.g., References 4, 23 through 27). To ensure reliability of EBSD data, all grains comprising three or fewer pixels were automatically "cleaned" from the maps using the grain-dilation option in the OIM ${ }^{\mathrm{TM}}$ software. Furthermore, to eliminate spurious boundaries caused by orientation noise, a lower limit boundary-misorientation cut-off of $2 \mathrm{deg}$ was employed. A 15 deg criterion was applied to differentiate low-angle boundaries (LABs) from high-angle boundaries (HABs).

\section{RESULTS AND DISCUSSION}

\section{A. Low-Magnification Overview}

1. Microstructure morphology

A low-magnification overview of the cryogenically rolled microstructure is presented in Figure 1, which shows only a selected portion (approximately onefourth) of the larger EBSD scan used for analysis.

In Figure 1(a), individual grains were colored

\footnotetext{
${ }^{*}$ Here and hereafter, the reader is referred to the online version of the paper to see the figures in color.
}

according to their crystallographic orientation relative to the sheet ND for the austenite and the $\alpha$-martensite using the typical color-code triangle. Remnants of the initial coarse-grain structure are clearly seen. This suggests that the grain-refinement process was not complete. However, as expected, cryogenic rolling did result in martensitic transformation (Figure 1(b)). The total fractions of $\alpha^{\prime}$-martensite and $\varepsilon$-martensite deduced from the low-resolution map were $\sim 35$ pct and $\sim 3$ pct, respectively. Considering the relatively coarse scan step size $(1 \mu \mathrm{m})$ as well as the very fine nature of the phases, these estimates were likely on the low side of the actual values.

The $\alpha^{\prime}$-martensite consisted of two different morphologies (Figure 1(b)): (a) relatively coarse domains resembling the original austenite grains and/or annealing twins, and (b) series of nearly parallel bands within prior-austenite grains. Surprisingly, the width of the $\alpha^{\prime}$-martensite bands varied noticeably from grain to grain. In some cases, they tended to overlap, thus consuming the parent austenite grain (e.g., circled area in Figure 1(b)). Considering the morphology of the $\alpha^{\prime}$-martensite, it appeared that this phase nucleated in narrow bands which grew subsequently in their thickness direction. It should be noted, however, that the observed variation of the martensite platelet thickness may also be due a section-plane (i.e., stereological) effect.

\section{Texture}

Orientation distribution functions for the austeniticand $\alpha^{\prime}$-martensitic phases calculated from the low-resolution map are summarized in Figure 2. The total area of the analyzed region was $4 \mathrm{~mm}^{2}$.

To a first approximation, the texture developed in the austenite comprised the superposition of two partial fibers: $\alpha\{110\}\langle u v w\rangle$ and $\beta$ (Figure 2(a)). Within the $\alpha$-fiber, strong Brass $\{110\}\langle 112\rangle$ and Goss $\{110\}\langle 100\rangle$ components were noted, whereas the $\beta$-fiber was 

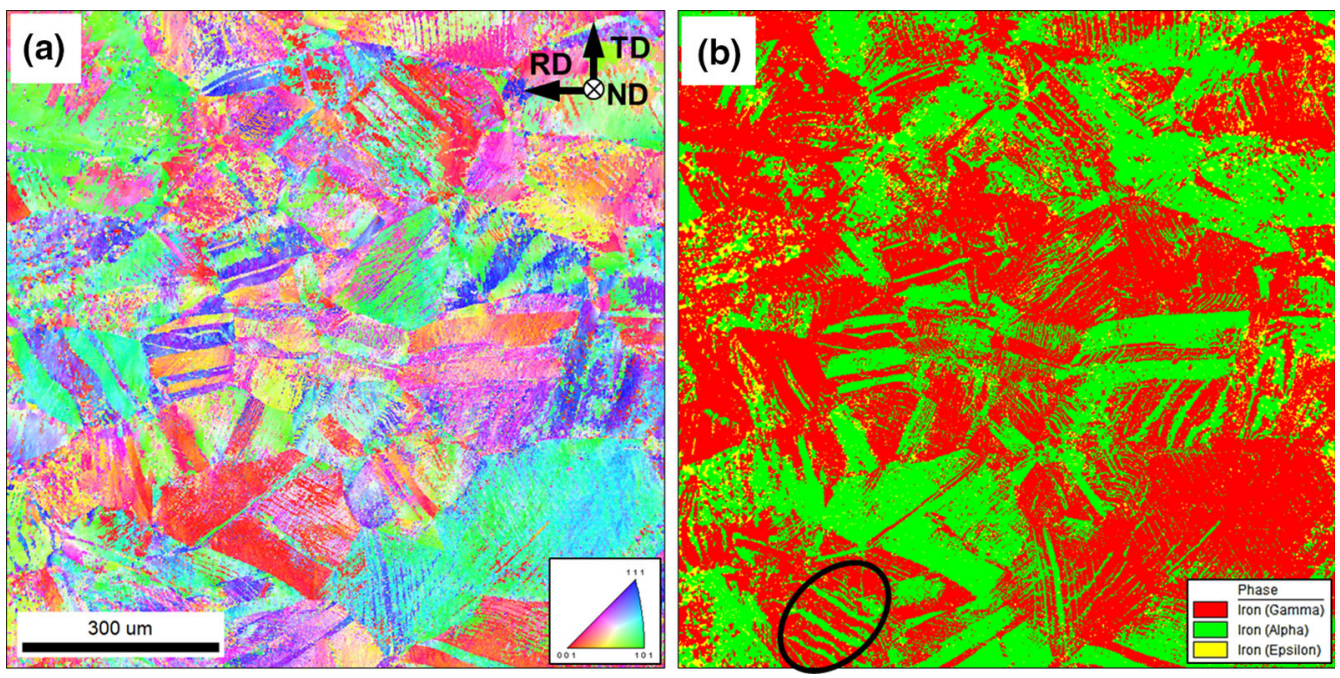

Fig. 1-Low-resolution EBSD results for the deformed microstructure: (a) ND direction inverse-pole figure map and $(b)$ phase map.

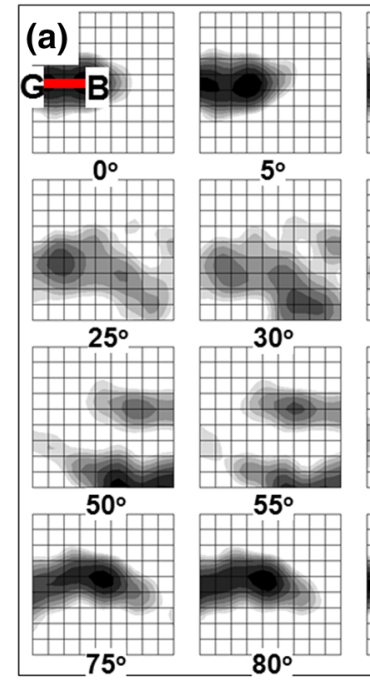

Texture Name: Harmonic: $L=16, H W=5.0$ Calculation Method: Harmonic Series Expansion Series Rank (I): 16

Gaussian Smoothing: $50^{\circ}$ Sample Symmetry. Orthotropic

Representation: Euler Angles (Bunge)

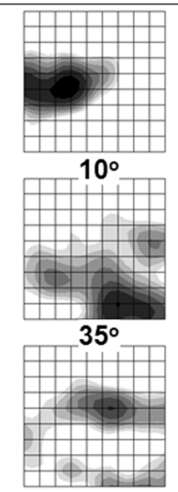

$60^{\circ}$

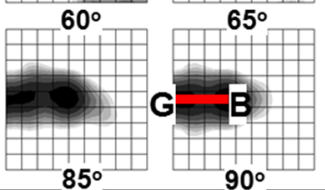

Constant Angle:

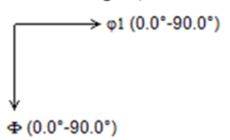

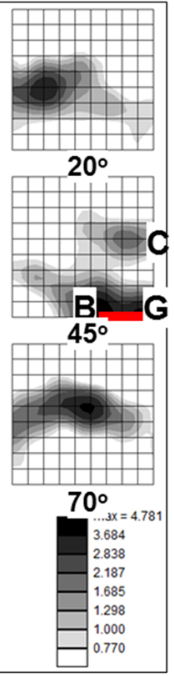

(b)

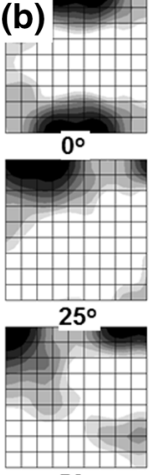

$50^{\circ}$

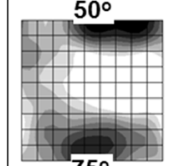

$75^{\circ}$
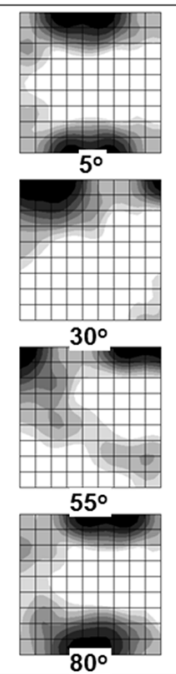

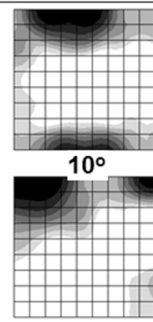

$35^{\circ}$

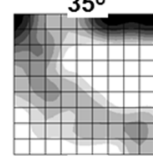

$60^{\circ}$

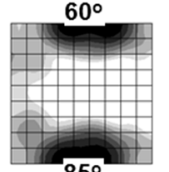

$85^{\circ}$

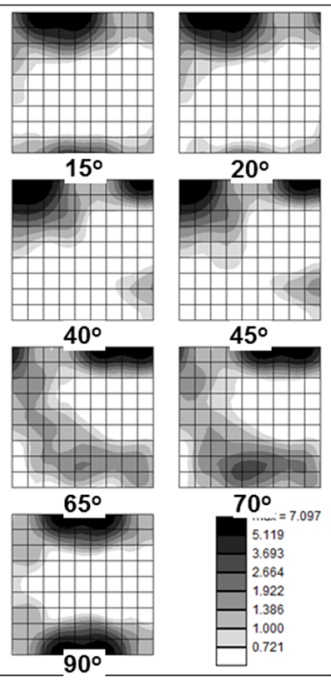

$\{110\}<u v w>\alpha$-fiber

$B=\{110\}<112>$ Brass $C=\{112\}<111>$ Copper

$G=\{110\}<100>$ Goss $S=\{123\}<634>S$

Fig. 2-Orientation distribution functions showing texture in $(a)$ austenite and $(b) \alpha^{\prime}$-martensite. The approximate positions of several ideal rolling orientations are indicated in (a).

dominated by the $\mathrm{S}\{123\}\langle 634\rangle$ and near-Copper $\{112\}\langle 111\rangle$ orientations (Figure 2(a), Table III). All texture components were characterized by considerable orientation spread; moreover, the Copper orientation was found to be slightly shifted from the expected position (Figure 2(a)). Generally, the measured texture for the austenite phase was broadly similar to that typically observed in moderately rolled face-centered-cubic metals. ${ }^{[47]}$

On the other hand, the texture developed in the $\alpha^{\prime}$-martensite (in terms of Bunge Euler angles) was dominated by the (35 deg;0 deg;0 deg) orientation (Figure 2(b)), which is not a typical rolling texture for body-centered-cubic metals (Figure 2(b)). The formation of similar texture in the deformation-induced martensite has been recently reported by Szpunar et al..$^{[15-17]}$ This texture component is suggested to originate from Copper orientation of the deformed austenite. ${ }^{[16]}$

\section{B. Analysis of Austenite-Rich Areas}

For a more detailed examination of microstructure evolution within the austenite phase as well as the details of martensite nucleation, a series of EBSD maps with a scan step size of $50 \mathrm{~nm}$ was obtained from austenite-rich 
Table III. Measured Fractions of Main Texture Components in Austenite (Within 15-deg Tolerance)

\begin{tabular}{lclr}
\hline Notation & Miller Indices & Euler Angles $\left(\varphi_{1} ; \Phi ; \varphi_{2}\right)$ & Fraction $($ Percent $)$ \\
\hline Brass & $\{110\}\langle 112\rangle$ & $(35 \mathrm{deg} ; 45 \mathrm{deg} ; 90 \mathrm{deg})$ & 16.0 \\
Goss & $\{110\}\langle 100\rangle$ & $(0 \mathrm{deg} ; 45 \mathrm{deg} ; 90 \mathrm{deg})$ & 7.2 \\
Copper & $\{112\}\langle 111\rangle$ & $(90 \mathrm{deg} ; 35 \mathrm{deg} ; 45 \mathrm{deg})$ & 6.0 \\
$S$ & $\{123\}\langle 634\rangle$ & $(59 \mathrm{deg} ; 37 \mathrm{deg} ; 63 \mathrm{deg})$ & 21.5 \\
\hline
\end{tabular}

The dominant components are italicised.
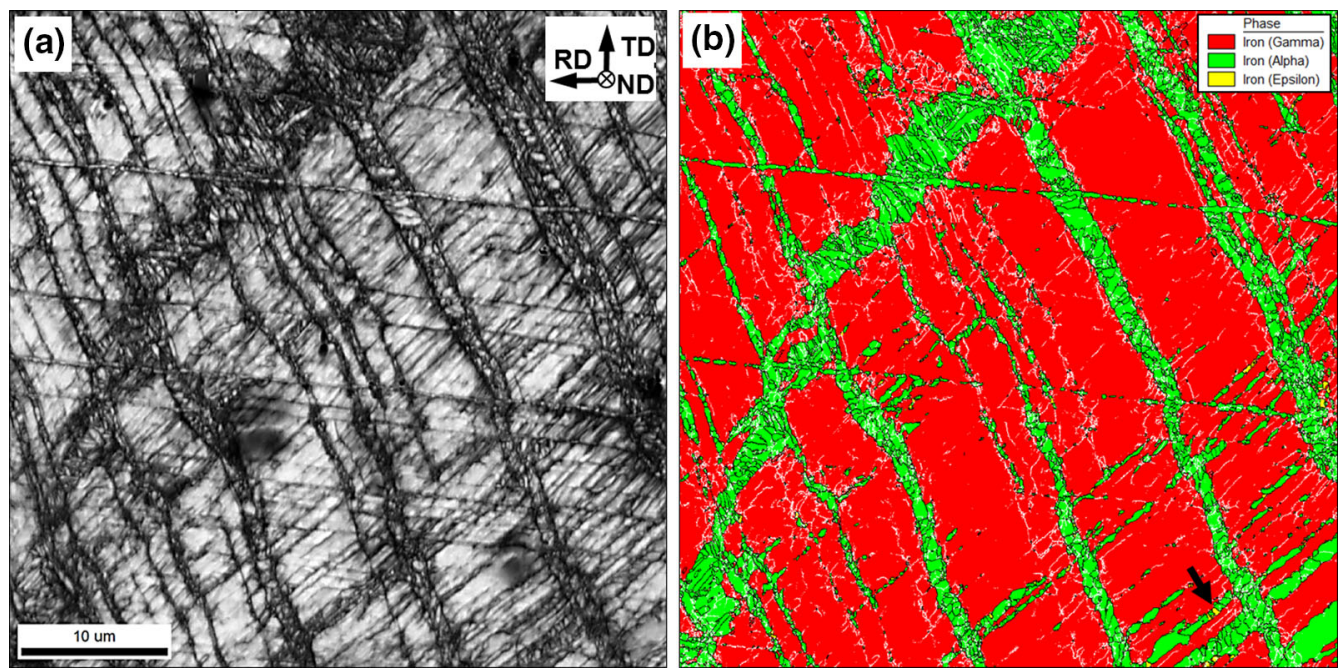

Fig. 3-Microstructure of an austenite grain with a crystallographic orientation close to Brass $\{110\}\langle 112\rangle$ : (a) Kikuchi-band-contrast map and (b) phase map. In (b), the arrow indicates the location of $\varepsilon$-martensite, and LABs and HABs are depicted by white and black lines, respectively.

areas. The observations were interpreted keeping in mind that the details of microstructure evolution may depend strongly on crystallographic orientation. For example, the $\alpha$-fiber may exhibit planar slip, the $\beta$-fiber may undergo mechanical twinning, and shear bands may develop in grains with the $\gamma\{111\}\langle u v w\rangle$ fiber orientation. ${ }^{[19]}$ Hence, to quantify this variability, EBSD maps were acquired from parent austenite grains with orientations close to Brass $\{110\}\langle 112\rangle$, Goss $\{110\}\langle 100\rangle$, $\mathrm{S}\{123\}\langle 634\rangle$, and $\mathrm{Y}\{111\}\langle 112\rangle$. Except for mechanical twinning, however, very similar microstructural features were found in all cases. Therefore, in-depth microstructural information for only one Brass grain is summarized in the present paper $^{\S}$ (Figures 3, 4, 5 and 6).

\footnotetext{
${ }^{\S}$ The measured orientation of the specific Brass grain is given in Supplementary Figure S-2.
}

Extensive, additional results are given in Supplementary Figures S3 through S14.

\section{Morphology}

Insight into the morphology of the microstructure was obtained from an examination of Kikuchi-band-contrast (image-contrast) and phase maps with superimposed grain boundaries (Figures 3(a) and (b), respectively). Kikuchi-band-contrast maps are based on measurement of the sharpness of Kikuchi patterns. The sharpness decreases in regions with crystal defects and thus provides images similar to optical, SEM, and TEM microscopy of the same area. For the present material, for example, the image in Figure 3(a) resembled the microstructure of various cold-rolled metals (including austenitic steels) in the literature (e.g., Reference 48). In particular, the microstructure was noticeably inhomogeneous, comprising several sets of intersecting deformation bands and regions with fine grains. The fine-grains consisted of $\alpha^{\prime}$-martensite with an average diameter of $\sim 0.3 \mu \mathrm{m}$ (Figure 3(b)). On the other hand, the microstructure of the austenite matrix was dominated by LABs and contained almost no deformation-induced HABs (Figure 3(b)). In fact, a significant fraction of the austenite boundaries had a misorientation below the resolution limit of EBSD, i.e., 2 deg, as seen by a comparison of Figures 3(a) and (b).

The phase map (Figure 3(b)) also revealed that the martensite phase was concentrated almost exclusively within the deformation bands. This agrees well with current theories of nucleation of deformation-induced martensite. ${ }^{[18]}$ In other austenite grains that were examined, the martensite was noted to nucleate within mechanical twins (Supplementary Figures S-3(b) and S-11(b)), but the prevalence of such observations was very limited; thus, the deformation bands were the preferred nucleation sites (Supplementary Figures S-3, 


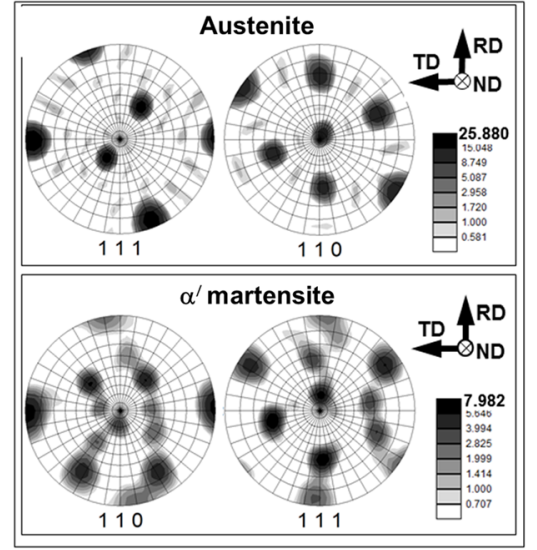

(a)

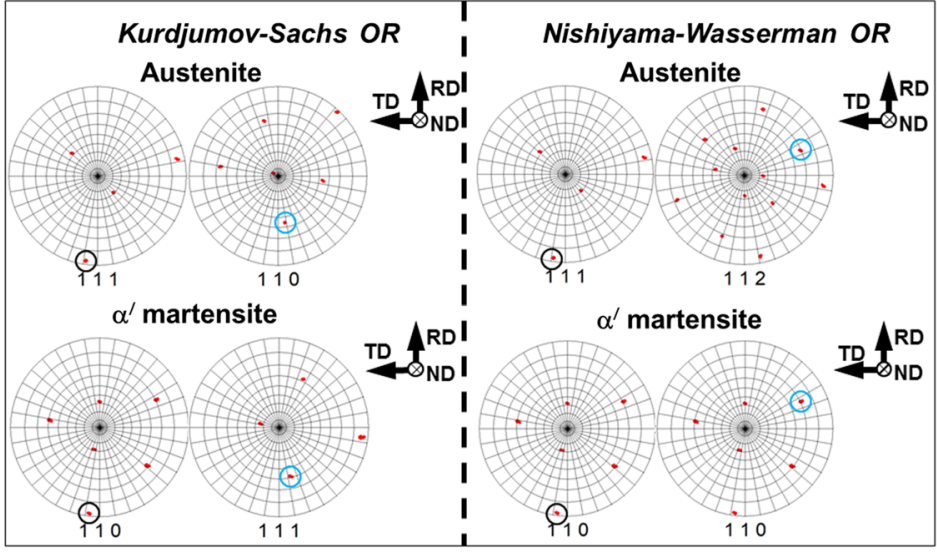

(b)

Fig. 4 -Crystallographic relationship between the austenite and $\alpha^{\prime}$ martensite in the austenite grain with a crystallographic orientation close to Brass $\{110\}\langle 112\rangle$ at $(a)$ the overall grain scale and $(b)$ a local scale. In (b), the closest related directions in the austenite and the $\alpha^{\prime}$ martensite are circled.

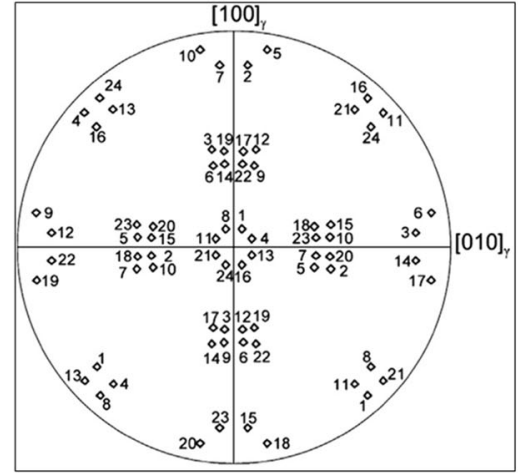

(a)

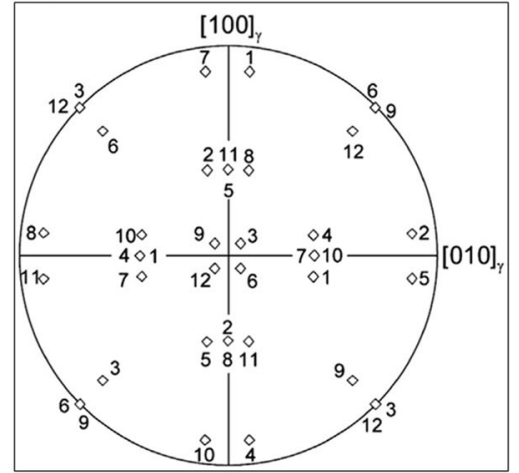

(b)

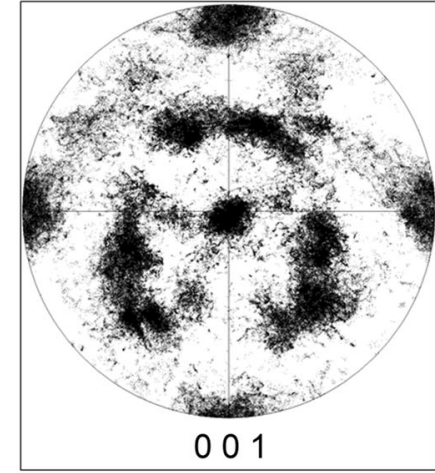

(c)

Fig. 5-Ideal $\{001\}$ pole figures showing orientations of martensite variants transformed from a single austenite grain according to (a) K-S orientation relationship (after Kitahara et $a l^{[49]}$ ), or $(b) \mathrm{N}-\mathrm{W}$ orientation relationship (after Kitahara et al. ${ }^{[50]}$ ), and $(c)$ measured pole figure. The measured pole figure was appropriately rotated to facilitate comparison with the ideal pole figures.

S-7, and S-11). Because a large fraction of the imposed strain was likely accommodated by the formation of deformation bands in which martensite was subsequently formed, grain refinement in the parent austenite phase was minimal.

\section{Orientation relationship}

The martensitic transformation is well known to follow an orientation relationship with the parent austenitic phase. For deformation-induced $\alpha^{\prime}$-martensite, the Kurdjumov-Sachs $(\mathrm{K}-\mathrm{S})$ relations, viz. $\{111\}_{\gamma} \|\{110\}_{\alpha^{\prime}}$ and $\langle 110\rangle_{\gamma}||\langle 111\rangle_{\alpha^{\prime}}$, is often observed, ${ }^{[18,22,30,34,35,40]}$ although other relationships are also possible. ${ }^{[36]}$ To confirm the $\mathrm{K}-\mathrm{S}$ relationship in the current work, appropriate pole figures for austenite and $\alpha^{\prime}$-martensite were derived from the entire EBSD map in Figure 3 and are compared with each other in Figure 4(a). Considering differences in crystal symmetry of the phases (resulting in different numbers of texture peaks), the corresponding pole figures appeared to match reasonably well, thus supporting the validity of the $\mathrm{K}-\mathrm{S}$ relation between the phases on a grain scale. A similar result was also obtained in other austenite grains (Supplementary Figures S-4(a), S-8(a), and S-12(a)).

On the other hand, the textures of both phases in Figure 4(a) were characterized by substantial orientation spreads, which tended to confound the interpretation of the orientation relationship. Hence, local orientations of adjacent austenite and $\alpha^{\prime}$-martensite material elements were also compared; an example of such a comparison is shown in Figure 4(b). For clarity, crystallographic directions in the austenite that are close to those in the $\alpha^{\prime}$-martensite are circled in the pole figures. It is seen that the $\langle 111\rangle$ and $\langle 110\rangle$ directions of the austenite deviated slightly $(\sim 5 \mathrm{deg})$ from the respective $\langle 110\rangle$ and $\langle 111\rangle$ directions of the $\alpha^{\prime}$-martensite, i.e., the measured orientation relationship did not satisfy the ideal $\mathrm{K}-\mathrm{S}$ relation. Similar deviations were also observed in other austenite grains (Supplementary Figures S-4(b), S-8(b), and S-12(b)).

The orientation deviation exceeded the angular resolution of EBSD $(\sim 2 \mathrm{deg})$ and thus probably reflected a real phenomenon. In this regard, it is worth noting that the thermally induced martensitic transformation in 


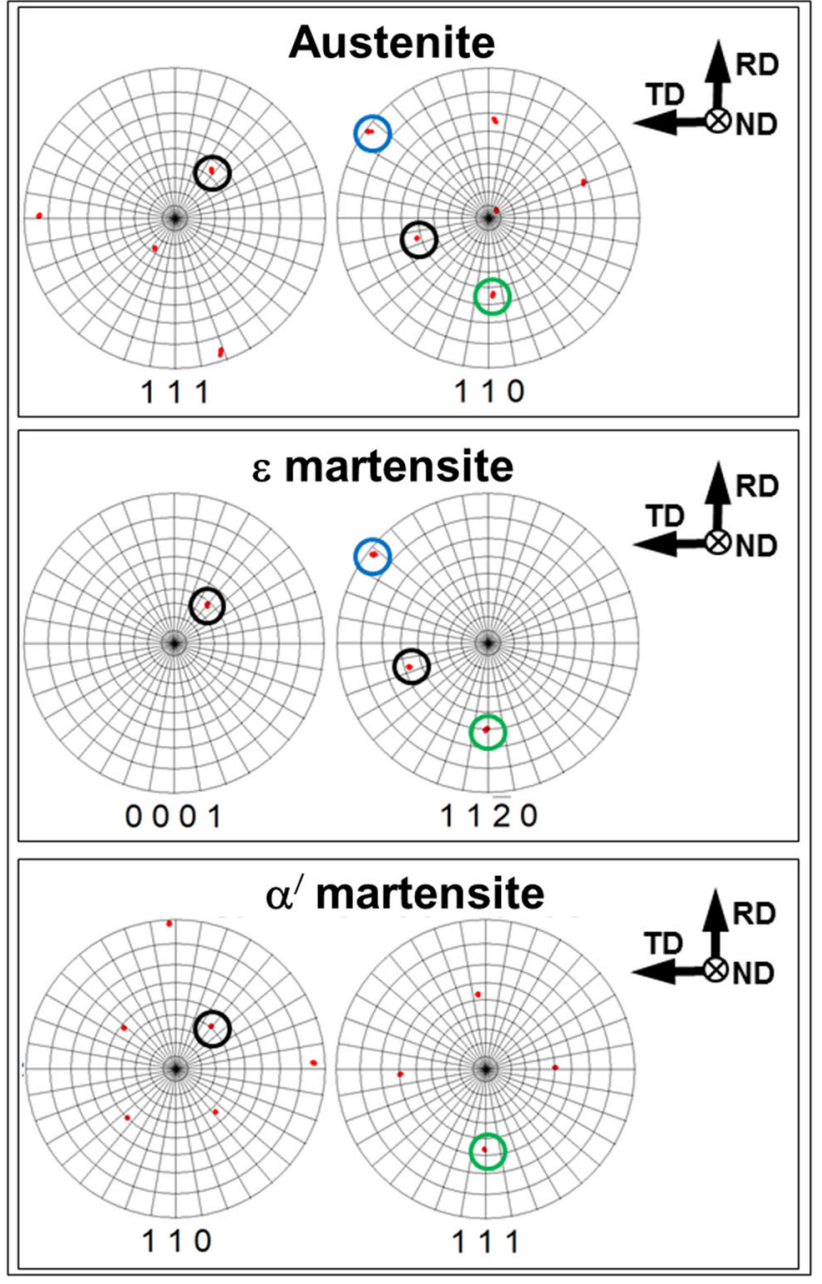

Fig. 6-Crystallographic relationship between the austenite, $\varepsilon$ martensite, and $\alpha^{\prime}$ martensite in the austenite grain with a crystallographic orientation close to Brass $\{110\}\langle 112\rangle$. The closest related directions in the austenite and the martensite phases are circled.

steels is sometimes governed by the Nishiyama-Wasserman $(\mathrm{N}-\mathrm{W})$ orientation relation, viz. $\{111\}_{\gamma} \|\{110\}_{\alpha^{\prime}}$ and $\langle 112\rangle_{\gamma}||\langle 110\rangle_{\alpha^{\prime}}$, and that the difference between $\mathrm{K}-\mathrm{S}$ and $\mathrm{N}-\mathrm{W}$ is also close to $5 \mathrm{deg}$. To examine this possibility, the appropriate pole figures were also compared (e.g., Figure 4(b)). It is seen that the measured orientation of the $\alpha^{\prime}$ martensite slightly deviated (by $\sim 5 \mathrm{deg}$ ) from the expected one. Therefore, the experimental orientation relationship satisfied neither the exact $\mathrm{K}-\mathrm{S}$ nor the $\mathrm{N}-\mathrm{W}$ models.

To gain additional insight into this issue, the martensite orientation data were extracted from several prior-austenite grains and compared with ideal orientations of the martensite variants expected from the $\mathrm{K}-\mathrm{S}$ and the $\mathrm{N}-\mathrm{W}$ orientation relationship. A typical example is shown in Figure 5. It is clear from Figure 5(c) that the measured martensite variants were characterized by significant orientation spread, and as a result the orientations expected for the $\mathrm{K}-\mathrm{S}$ and $\mathrm{N}-\mathrm{W}$ variants overlapped. Nevertheless, considering the characteristic circular appearance for the variants in the measured pole figure (Figure 5(c)), the orientation relation was suggested to be closer to the $\mathrm{K}-\mathrm{S}$ (Figure 5(a)) rather than to N-W (Figure 5(b)).

As discussed in the previous section, the $\alpha^{\prime}$-martensite was nucleated preferentially in deformation bands. The austenite in these bands likely underwent local crystallographic rotations before the martensitic transformation. Therefore, the discrepancy in the orientation relationship (Figure 4(b)) as well as significant orientation spread (Figure 5) was likely characteristic of the local strain experienced by the austenite before the transformation. Considering the $5 \mathrm{deg}$ rotation as a threshold for the martensitic transformation, it seems that the transformation prevents strain accumulation in the austenite and thus mitigates grain-refinement in this phase, as suggested above.

The possibility of the $\gamma \rightarrow \varepsilon \rightarrow \alpha^{\prime}$ transformation sequence was also investigated via examination of appropriate pole figures (e.g., Figure 6). In this case, the $\gamma \rightarrow \varepsilon$ transformation followed nearly the ideal $\{111\}_{\gamma}||\{0001\}_{\varepsilon}$ and $\langle 110\rangle_{\gamma}||\langle 11-20\rangle_{\varepsilon}$ orientation relation. The excellent orientation relationship between the phases is thought to be attributable to a specific transformation mechanism involving simple overlapping of stacking faults. ${ }^{[2]}$ Moreover, all of the orientation peaks of the $\varepsilon$ phase coincided with the corresponding directions in the austenite (Figure 6). This finding thus provided evidence for the formation of only one specific crystallographic variant of the $\varepsilon$-martensite among all possible ones, i.e., variant selection was very strong. A similar effect was found in $\mathrm{Y}$-oriented austenite grains ${ }^{\S \S}$

\footnotetext{
${ }^{\S}$ In the examined Goss and $\mathrm{S}$ grains, the detected fraction of the $\varepsilon$-martensite was low, and thus reliable measurements were difficult.
}

(supplementary Figure S-12(c)). By contrast, the $\varepsilon \rightarrow \alpha^{\prime}$ transformation, governed by the Burgers relationship $\{0001\}_{\varepsilon}||\{110\}_{\alpha^{\prime}}$ and $\langle 11-20\rangle_{\varepsilon}||\langle 111\rangle_{\alpha^{\prime}}$, involved weaker variant selection (Figure 6 and Supplementary Figure S-12(c)). Similar to the $\gamma \rightarrow \alpha^{\prime}$ transformation discussed above, the measured orientation $\alpha^{\prime}$-martensite was found to deviate significantly from the predicted one (Figure 6 and Supplementary Figure S-12(c)).

The present results thus indicate that both transformation sequences, i.e., $\gamma \rightarrow \alpha^{\prime}$ and $\gamma \rightarrow \varepsilon \rightarrow \alpha^{\prime}$ contribute to the formation of the $\alpha^{\prime}$-martensite. The specific contribution of each mechanism and their interaction warrants further research, however.

\section{Texture of $\alpha^{\prime}$-martensite}

The orientation distribution function of the $\alpha^{\prime}$-martensite revealed that the martensitic phase nucleated in the near-Brass grain was dominated by the (45 deg;0 deg;0 deg) orientation, thus being broadly similar to the global texture of the $\alpha^{\prime}$-martensite (Figures 7 vs 2(b)). This observation enabled a number of conclusions. First, the texture of the martensitic phase presumably originated from phase transformation and not from deformation. If so, the $\alpha^{\prime}$-martensite probably 


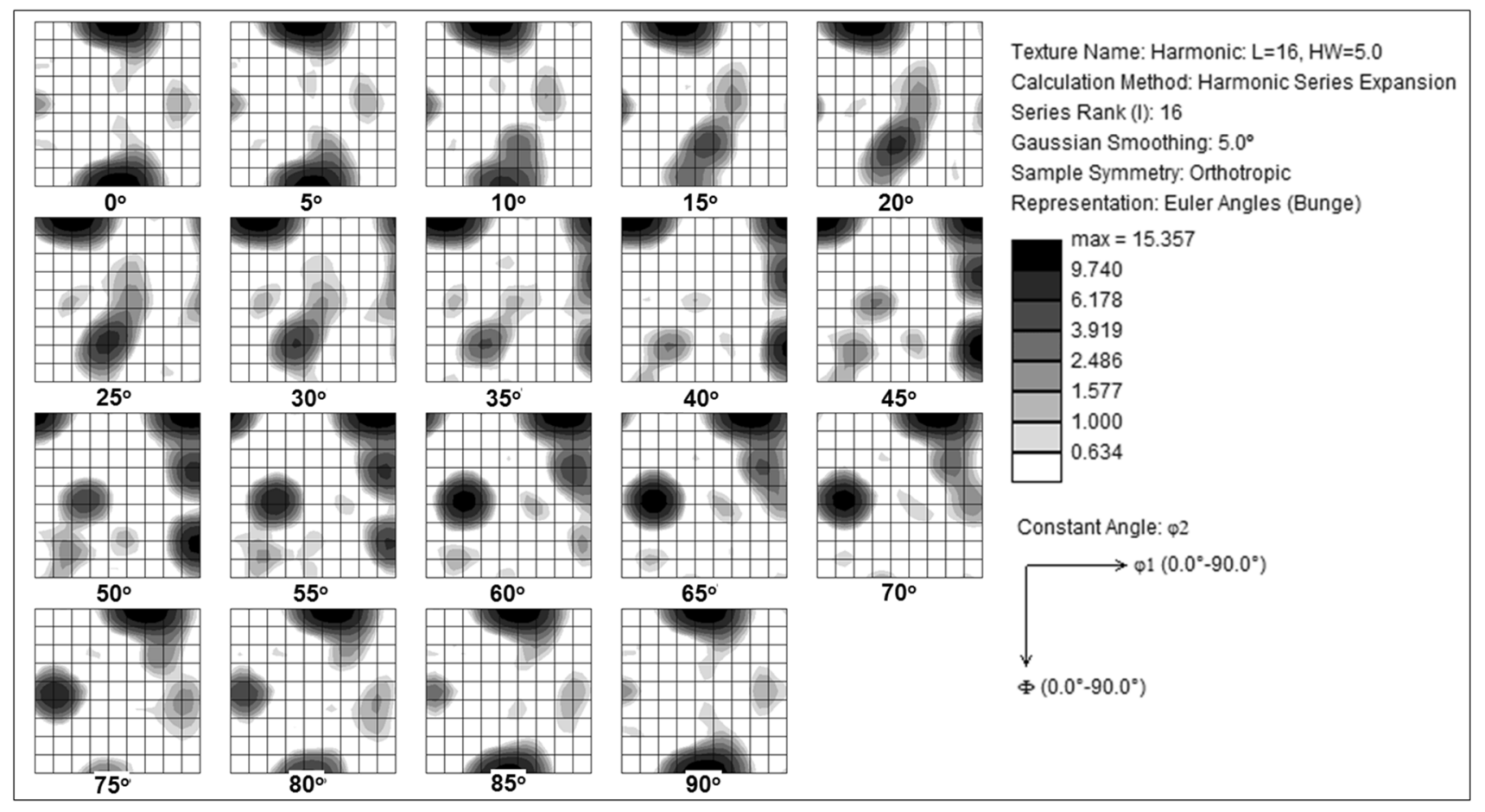

Fig. 7-Orientation distribution function of the $\alpha^{\prime}$-martensite nucleated in the austenite grain with a crystallographic orientation close to Brass $\{110\}\langle 112\rangle$.

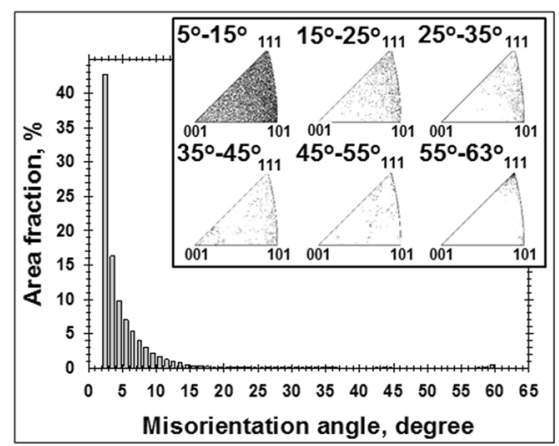

(a)

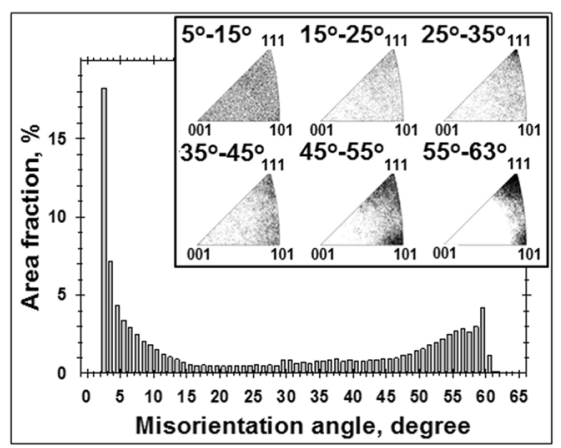

(b)

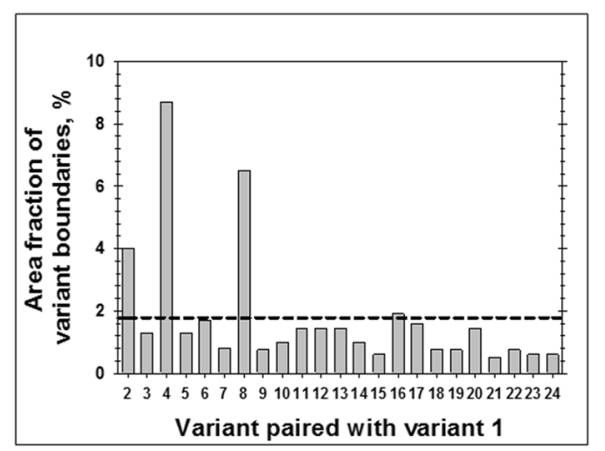

(c)

Fig. 8-Misorientation data derived from the austenite grain with a crystallographic orientation close to Brass $\{110\}\langle 112\rangle$ : (a) Distributions for austenite, $(b)$ distribution for $\alpha^{\prime}$-martensite, and (c) variant-pairing-frequency histogram for the $\alpha^{\prime}$-martensite. In (a) and (b), misorientation-axis distributions are shown as insets. In (c), the horizontal broken line represents the fraction of intervariant misorientations expected for a random distribution of variants (i.e., the no-variant-selection condition).

experienced no significant strain during rolling, i.e., the plastic deformation was primarily concentrated within the austenite.

On the global scale, the $\alpha^{\prime}$-martensite originated preferentially from austenite grains with the near-Brass orientation. Among the other austenite grains/texture components, S grains probably also contributed measurably to martensite formation (Supplementary Figure S-9(b)). The contributions of other austenite orientations were probably small (Supplementary Figures S-5(b) and S-13(b)). This conclusion is consistent with the prevalence of Brass and $\mathrm{S}$ orientations in the final texture of the austenite (Table III)

\section{Misorientation distributions}

As expected, the misorientation distribution for the austenite phase (Figure 8(a)) was dominated by LABs, thereby providing quantitative evidence for the relative absence of grain-refinement in this phase. The misorientation measurements in the austenite Brass grain revealed a very low fraction of twin boundaries $\Sigma 3$ (Figure 8(a)). This result is most likely attributable to the relatively low Schmid factor in the Brass orientation. ${ }^{[19]}$ However, the misorientation distributions of other texture components were characterized by a significant fraction of twin boundaries (Supplementary Figures S-6(a) and S-14(a)). 
In contrast to the austenite, the martensitic phase was characterized by a significant proportion of $\mathrm{HABs}$ (Figure 8(b)). Furthermore, the HAB distribution exhibited very specific misorientation angles and misorientation axes (Figure 8(b)). Nearly similar misorientation distributions were also observed in the $\alpha^{\prime}$-martensite nucleated in other austenite grains (Supplementary Figures S-6(b), S-10(b), and S-14(b)).

Assuming that the $\alpha^{\prime}$-martensite experienced no significant strain during rolling (as suggested above), the nature of its misorientation distribution can be explained in terms of preferential variant selection. Due to the crystal symmetry of the $\gamma$ and $\alpha^{\prime}$ phases, there are 24 possible variants that obey the $\mathrm{K}-\mathrm{S}$ relation, and the misorientation between given pairs of variants is very specific (Supplementary Table S-1). For semi-quantitative analysis of variant selection during the martensitic transformation, intervariant misorientations are often represented as those between V1 and other variants, as shown in Supplementary Table S-2. Hence, to examine the relationship between the measured misorientation distribution for the $\alpha^{\prime}$-martensite and the crystallographic variants in the present work, the area fractions of variant boundaries were determined (Figure 8(c)). The result (Figure 8(c)) indicated that the variant boundaries comprised a significant portion of the misorientations measured in the $\alpha^{\prime}$-martensite (Figure 8(b)), thus supporting the hypothesis that the martensitic phase experienced little strain during rolling. Moreover, Figure 8(c) also indicates a clear preference for $\mathrm{V} 1 / \mathrm{V} 2, \mathrm{~V} 1 / \mathrm{V} 4$, and $\mathrm{V} 1 / \mathrm{V} 8$ variant boundaries, thus providing evidence for noticeable non-random variant selection during the martensitic transformation. A similar effect was found in all of the austenite grains that were studied (Supplementary Figures S-6(c), S-10(c), and S-14(c)).

In addition to the inter-variant boundaries, a crystallographic preference for $\sim 30$ to $35 \mathrm{deg}\langle 111\rangle$ misorientations was found in the $\alpha^{\prime}$-martensite phase (Figure 8(b) and Supplementary Figures S-6(b), S-10(b), and S-14(b)). These misorientations are not associated with either the $\mathrm{K}-\mathrm{S}$ or $\mathrm{N}-\mathrm{W}$ orientation relationships, and therefore their origin is not clear.

\section{Analysis of Martensite-Rich Areas}

Considering the well-known sensitivity of deformation processes to crystallographic orientation as well as grain-to-grain interactions, the fairly inhomogeneous distribution of the martensite in Figure 1(b) may reflect a variation of the phase transformation rate from grain to grain. If so, martensite-rich areas may be considered as those representing an advanced stage of the martensitic transformation. Therefore, a comparison of their microstructural characteristics with those of austenite-rich areas can provide insight into microstructure evolution. This approach was used in the present section. It should be emphasized, however, that the observed difference in the martensite content may simply be due to a section-plane (i.e., stereology) effect. Therefore, the results discussed below require further validation by appropriate measurements on the samples subjected to different levels of reduction.

To characterize the microstructure of the martensite-rich areas, a series of EBSD maps with a scan step size of $50 \mathrm{~nm}$ was obtained. For this work, attention was focused on the microstructure with the dominant texture component (Figure 2(b)), i.e., a region with a crystallographic orientation close to (25 deg;0 deg;0 deg) (Supplementary Figure S-15(a)). In this case, the martensite likely originated from austenite with a near-Brass orientation (Supplementary Figure S-15(b)). For comparative purposes, additional maps were also obtained from martensite-rich areas with crystallographic orientations close to (35 deg;35 deg;45 deg) (Supplementary Figure S-17(a)) and (35 deg;40 deg;0 deg) (Supplementary Figure S-21(a)). In the former case, the martensite probably also transformed from the near-Brass austenite grain (Supplementary Figure S-17(b)), whereas for the latter one from a near-Y orientation austenite grain (Supplementary Figure S-21(b)). In all instances, however, the microstructures showed a broad similarity. Thus, only microstructure data from the (25 deg;0 $\mathrm{deg} ; 0 \mathrm{deg})$ orientation are shown in the present paper (Figures 9, 10 and 11) while the remaining results are given in Supplementary Figures S-15 to S-23.

\section{Morphology}

The typical microstructure of a martensite-rich area is shown in Figure 9. The Kikuchi-band-contrast map appeared to reveal an ultrafine structure (Figure 9(a)). However, the corresponding phase map (Figure 9(b)) evidenced that a significant portion of the martensite grain boundaries had misorientations below the limit detectable by EBSD. For the most part, the martensite grain structure was noticeably coarser than that observed during the nucleation stage (e.g., Figures 9(b) vs 3(b)). A relatively coarse microstructure was also found in the martensite-rich area with the orientation (35 deg;35 deg;45 deg) (Supplementary Figure S-16(b)). A possible reason for the coarsening of martensite is discussed in Section III-C-3.

Extensive twinning was also found in the retained austenite (Figure 9(b)). As mentioned above, grains with a near-Brass orientation had a relatively low Schmid factor for twinning. Therefore, the observed activation of this mechanism may be attributable to internal stresses associated with the martensite transformation. On the other hand, the observation of mechanical twins in retained austenite at a late stage in the phase-transformation process may indicate a relative difficulty for twin-induced martensite nucleation in type 321 stainless steel.

\section{Orientation relationship}

Figure 10 summarizes orientation relation between the austenite and martensite phases. On the overall grain scale, the orientation relations appeared to become less applicable in comparison with the observations for the martensite-nucleation stage (Figure 10(a) vs Figure 4(a)). This trend may be attributable to mechanical twinning in the retained austenite which produces new orientations in this phase. On the 

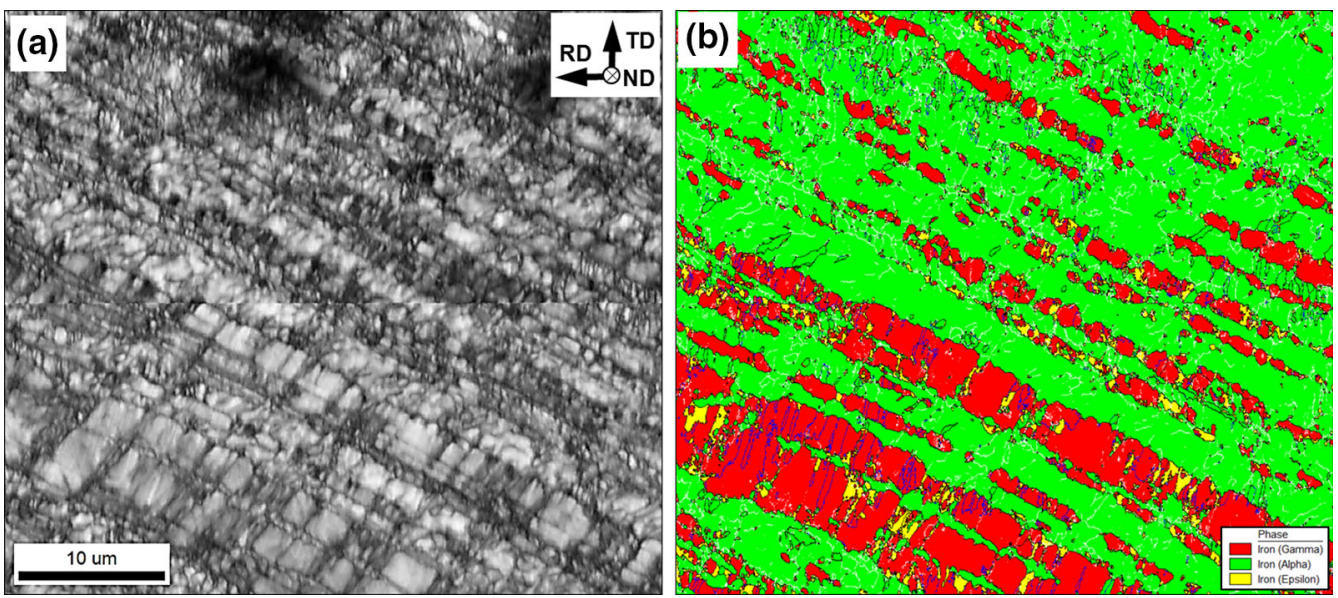

Fig. 9-Microstructure of the martensite-rich region with crystallographic orientation close to (25 deg/55 deg;0 deg;0 deg): (a) Kikuchi-band-contrast map and (b) phase map. In (b), LABs, HABs, and $\Sigma 3$ boundaries are depicted by white, black, and blue lines, respectively.
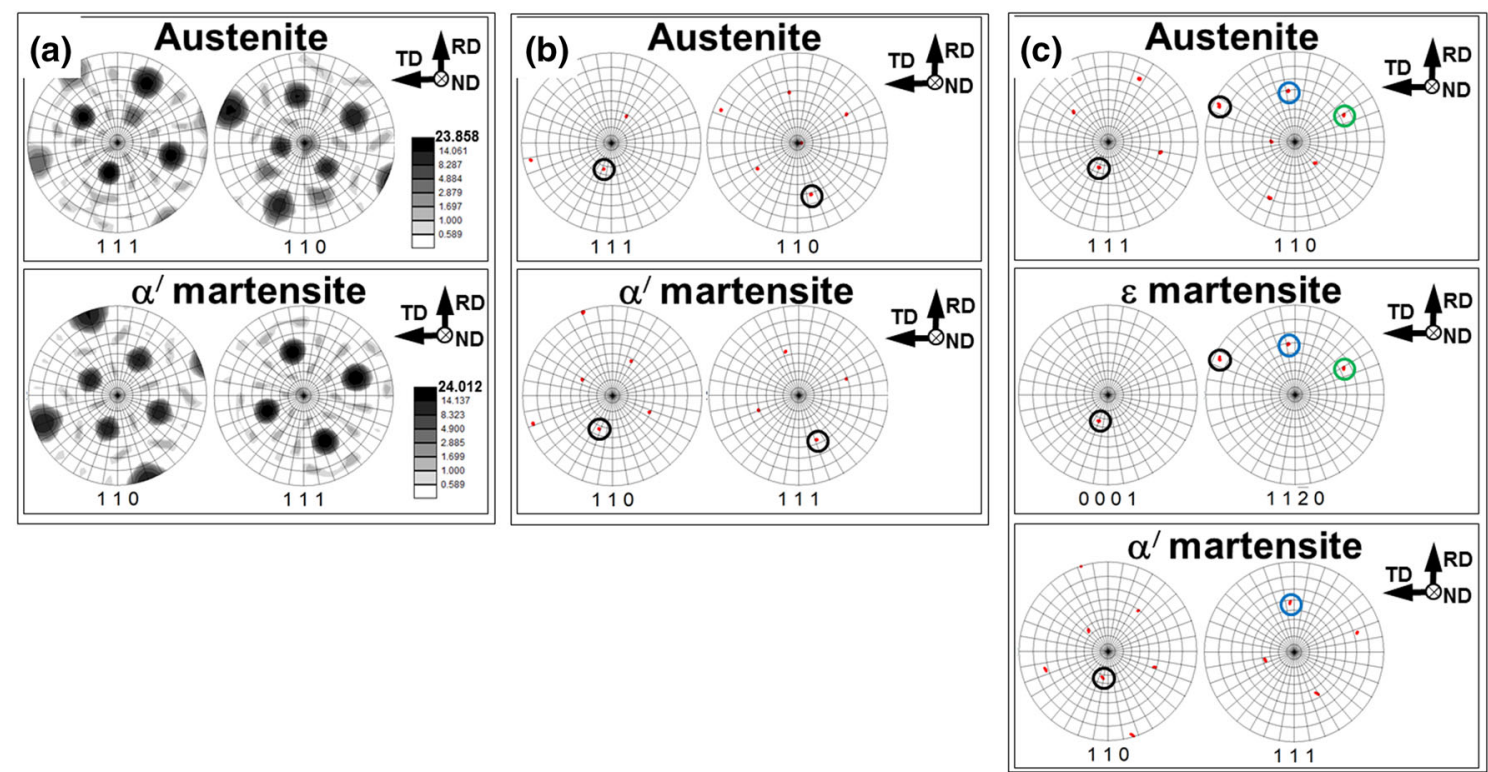

Fig. 10 - Crystallographic relationship between the austenite and martensite phases in the martensite-rich region with a crystallographic orientation close to $(25 \mathrm{deg} / 55 \mathrm{deg} ; 0 \mathrm{deg} ; 0 \mathrm{deg})$ on $(a)$ the overall grain scale and $(b)$ a local scale. In $(\mathrm{b})$ and $(c)$, the closest related directions in the austenite and the martensite phases are circled.

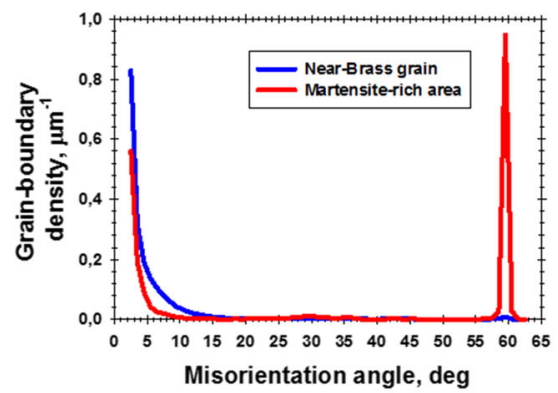

(a)

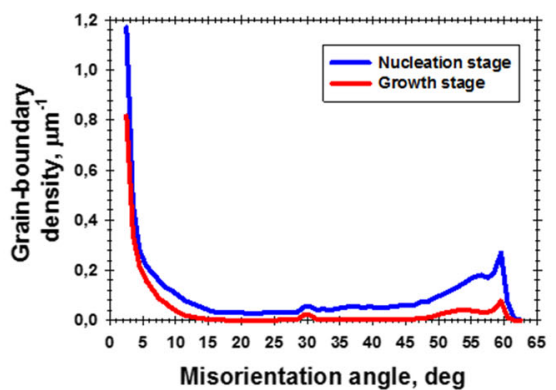

(b)

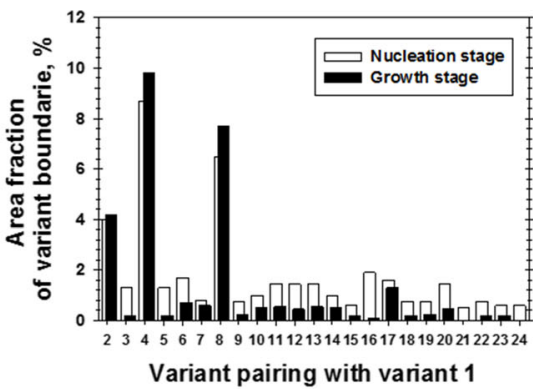

(c)

Fig. 11-Evolution of grain-boundary density in $(a)$ austenite and $(b)$ in $\alpha^{\prime}$-martensite during growth of the martensitic phase with crystallographic orientation close to $(25 \mathrm{deg} / 55 \mathrm{deg} ; 0 \mathrm{deg} ; 0 \mathrm{deg})$. In (c) the variant-pairing frequency in $\alpha^{\prime}$-martensite is shown. The processes are examined via comparison of the misorientation data derived from a near-Brass grain (nucleation stage) and from the martensite-rich region. 
local scale, however, no significant changes were found (Figures 10(b) and (c), Supplementary Figures S-18(b), S-18(c) and S-22(b), S-22(c)).

\section{Misorientation distribution}

Misorientation data derived from the retained austenite with the near-Brass orientation (discussed in Section III-B-4) and $\alpha^{\prime}$-martensite (Figure 11) gave insight into microstructure evolution during growth of the martensitic phase. The data in Figures 11(a) and (b) are expressed in terms of grain-boundary density, i.e., the measured grain boundary length for a given misorientation angle divided by the area of the EBSD map. This metric provides a direct comparison of grain-boundary characteristics, thus enabling more reliable interpretation of the key physical mechanisms governing microstructure evolution.

The retained austenite was characterized by a significant reduction in the density of LABs (Figure 11(a)). A similar observation was also made in the martensite-rich area with the (35 deg;35 deg;45 deg) orientation (Supplementary Figure S-19(a)). This trend agrees with preferential martensite nucleation in deformation bands (as discussed in Section III-B-1), which eliminates deformation-induced boundaries from the austenite. It also underscores again the competitive character of the deformation and phase-transformation processes and thus a disruption of the grain-refinement process in the austenite by the martensitic transformation. By contrast, Figure 11(a) reveals a significant increase in twin-boundary density, thus mirroring extensive twinning in the retained austenite, as discussed above. A similar effect was also found in the martensite-rich area with the (35 deg;35 deg;45 deg) orientation (Supplementary Figure S-19(a)). In general, it thus appeared that twinning was the primary (or even the sole) mechanism for the formation of HABs in the austenitic phase.

The $\alpha^{\prime}$-martensite was also characterized by a significant reduction in total grain-boundary density (Figure 11(b), Supplementary Figure S-19(b)). This observation reflected the coarsening of martensite mentioned in Section III-C-1. Assuming that the misorientation distribution in the $\alpha^{\prime}$-martensite is governed by inter-variant boundaries, this interesting phenomenon may also be explained in terms of variant selection. Per Figure 11(c) (and Supplementary Figures S-19(c) and S-23(c)), the growth of the martensitic phase increased the content of $\mathrm{V} 1 / \mathrm{V} 2, \mathrm{~V} 1 / \mathrm{V} 4$, and $\mathrm{V} 1 / \mathrm{V} 8$ boundaries, whereas the remaining inter-variant boundaries tended to disappear. It may be suggested therefore that variant selection became more pronounced during the growth stage of the martensitic transformation.

\section{SUMMARY AND CONCLUSIONS}

EBSD was applied to investigate microstructure evolution during cryogenic rolling of type 321 metastable austenitic stainless steel. The main conclusions from this work are as follows:
1. As expected, cryogenic rolling promoted a martensitic transformation. The martensite was found to nucleate preferentially in deformation bands although evidence of twin-induced nucleation was also found. The nucleation of martensite in the most heavily deformed areas mitigated the gradual LAB-to-HAB evolution and thus suppressed grain-refinement of the austenite via the typical grain-subdivision process. Mechanical twinning was the preponderant mechanism providing $\mathrm{HAB}$ formation in the austenite.

2. Evidence of two transformation sequences, viz. $\gamma \rightarrow \alpha^{\prime}$ and $\gamma \rightarrow \varepsilon \rightarrow \alpha^{\prime}$, were found. Both transformation paths were shown to follow the general orientation relations $\{111\}_{\gamma}\left\|\{0001\}_{\varepsilon}\right\|\{110\}_{\alpha^{\prime}}$ and $\langle 110\rangle_{\gamma}||\langle 11-20\rangle_{\varepsilon}||\langle 111\rangle_{\alpha^{\prime}}$. In both cases, however, the measured orientations of the $\alpha^{\prime}$-martensite deviated significantly ( $\sim 5 \mathrm{deg})$ from the predicted locations. This effect was attributed to strain-induced crystallographic rotations within the austenite deformation bands prior to the martensitic transformation.

3. Both martensitic transformations were characterized by variant selection. In the case of $\varepsilon$-martensite, only one variant was found to develop, and thus the selection was exceptionally strong.

4. The variant-selection effect appeared to strengthen during the growth stage of the $\alpha^{\prime}$ martensitic transformation.

\section{ACKNOWLEDGMENTS}

Financial support from the Russian Fund for Fundamental Research (Project No. 17-42-020426) is gratefully acknowledged. The authors would also like to thank P. Klassman for technical assistance during cryogenic rolling.

\section{ELECTRONIC SUPPLEMENTARY MATERIAL}

The online version of this article (https://doi.org/10. 1007/s11661-018-4919-2) contains supplementary material, which is available to authorized users.

\section{REFERENCES}

1. R. Valiev: Nat. Mater., 2004, vol. 8, pp. 511-16, https://doi.org/ $10.1038 /$ nmat 1180 .

2. K. Tomimura, S. Takaki, S. Tanimoto, and Y. Tokunaga: ISIJ Int., 1991, vol. 31, pp. 721-27.

3. K. Tomimura, S. Takaki, and Y. Tokunaga: ISIJ Int., 1991, vol. 31, pp. 1431-37.

4. Y. Lu, B. Hutchinson, D.A. Molodov, and G. Gottstein: Acta Mater., 2010, vol. 58, pp. 3079-90, https://doi.org/10.1016/ j.actamat.2010.01.045. 
5. G.S. Sun, L.X. Du, J. Hu, and R.D.K. Misra: Mater. Sci. Eng. A, 2018, vol. 709, pp. 254-64, https://doi.org/10.1016/j.msea.2017. 10.054 .

6. M. Odnobokova, A. Belyakov, N. Enikeev, D.A. Molodov, and R. Kaibyshev: Mater. Sci. Eng. A, 2017, vol. 689, pp. 370-83, https://doi.org/10.1016/j.msea.2017.02.073.

7. A. Kisko, A.S. Hamada, J. Talonen, D. Porter, and L.P. Karjalainen: Mater. Sci. Eng. A, 2016, vol. 657, pp. 359-70, https://doi.org/10.1016/j.msea.2016.01.093.

8. R.D.K. Misra, Z. Zhang, P.K.C. Venkatasurya, M.C. Somani, and L.P. Karjalainen: Mater. Sci. Eng. A, 2010, vol. 527, pp. 7779-92, https://doi.org/10.1016/j.msea.2010.08.051.

9. S. Rajasekhara, L.P. Karjalainen, A. Kyröläinen, and P.J. Ferreira: Mater. Sci. Eng. A, 2010, vol. 527, pp. 1986-96, https:// doi.org/10.1016/j.msea.2009.11.037.

10. M. Eskandari, A. Najafizadeh, and A. Kermanpur: Mater. Sci. Eng. A, 2009, vol. 519, pp. 46-50, https://doi.org/10.1016/ j.msea.2009.04.038.

11. B. Ravi Kumar, A.K. Singh, B. Mahato, P.K. De, N.R. Bandyopadhyay, and D.K. Bhattacharya: Mater. Sci. Eng. A, 2006, vol. 429, pp. 205-11, https://doi.org/10.1016/j.msea.2006.05. 107.

12. M.C. Somani, P. Juntunen, L.P. Karjalainen, R.D.K. Misra, and A. Kyrolainen: Metall. Mater. Trans. A, 2009, vol. 40A, pp. 729-44.

13. S. Rajasekhara, P.J. Ferreira, L.P. Karjalainen, and A. Kyrolainen: Metall. Mater. Trans. A, 2007, vol. 38A, pp. 1202-10.

14. D.L. Johannsen, A. Kyrolainen, and P.J. Ferreira: Metall. Mater. Trans. A, 2006, vol. 37A, pp. 2325-38.

15. M. Nezakat, H. Akhiani, S.M. Sabet, and J. Szpunar: Mater. Charact., 2017, vol. 123, pp. 115-27, https://doi.org/10.1016/ j.matchar.2016.11.019.

16. M. Nezakat, H. Akhiani, M. Hoseini, and J. Szpunar: Mater. Charact., 2014, vol. 98, pp. 10-17, https://doi.org/10.1016/ j.matchar.2014.10.006.

17. A.A. Tiamiyu, A.G. Odeshi, and J.A. Szpunar: JMEPEG, 2018, vol. 27, pp. 889-904, https://doi.org/10.1007/s11665-018-31806.

18. K.H. Lo, C.H. Shek, and J.K.L. Lai: Mater. Sci. Eng. R, 2009 , vol. 65, pp. 39-104, https://doi.org/10.1016/j.mser.2009.03.001.

19. J. Hirsch, K. Lucke, and M. Hatherly: Acta Metall., 1988, vol. 36, pp. 2905-27, https://doi.org/10.1016/0001-6160(88)90174-5.

20. L.J. Teutonico: Acta Metall., 1963, vol. 11, pp. 1283-89, https:// doi.org/10.1016/0001-6160(63)90023-3.

21. J.W. Christian and S. Mahajan: Prog. Mater. Sci., 1995, vol. 39, pp. 1-157, https://doi.org/10.1016/0079-6425(94)00007-7.

22. J.W. Brooks, M.H. Loretto, and R.E. Smallman: Acta Metall., 1979, vol. 27, pp. 1839-47, https://doi.org/10.1016/0001-6160(79) 90074-9.

23. A. Kermanpur, P. Behjati, J. Han, A. Najafizadeh, and Y.-K. Lee: Mater. Des., 2015, vol. 82, pp. 273-80, https://doi.org/10.1016/ j.matdes.2015.05.075.

24. C. Ullrich, R. Eckner, L. Krüger, S. Martin, V. Klemm, and D. Rafaja: Mater. Sci. Eng. A, 2016, vol. 649, pp. 390-99, https:// doi.org/10.1016/j.msea.2015.10.021.

25. I.R. Souza Filho, K.D. Zilnyk, M.J.R. Sandim, R.E. Bolmaro, and H.R.Z. Sandim: Mater. Sci. Eng. A, 2017, vol. 702, pp. 161-72, https://doi.org/10.1016/j.msea.2017.07.010.

26. J. Chen, W. Zhang, Z. Liu, and G. Wang: Mater. Sci. Eng. A, 2017, vol. 698, pp. 198-205, https://doi.org/10.1016/j.msea.2017. 05.059 .

27. X. Zhang and T. Sawaguchi: Acta Mater., 2018, vol. 143, pp. 237-47, https://doi.org/10.1016/j.actamat.2017.10.009.

28. G.B. Olson and M. Cohen: Metall. Trans. A, 1975, vol. 6A, pp. 791-95, https://doi.org/10.1007/BF02672301.
29. A.K. De, D.C. Murdock, M.C. Mataya, J.G. Speer, and D.K. Matlock: Scripta Mater., 2004, vol. 50, pp. 1445-49, https:// doi.org/10.1016/j.scriptamat.2004.03.011.

30. T.-H. Lee, E. Shin, C.-S. Oh, H.-Y. Ha, and S.-J. Kim: Acta Mater., 2010, vol. 58, pp. 3173-86, https://doi.org/10.1016/ j.actamat.2010.01.056

31. A. Das, S. Sivaprasad, P.C. Chakraborti, and S. Tarafder: Mater. Sci. Eng. A, 2011, vol. 528, pp. 7909-14, https://doi.org/10.1016/ j.msea.2011.07.011.

32. Y.F. Shen, X.X. Li, X. Sun, Y.D. Wang, and L. Zuo: Mater. Sci. Eng. A, 2012, vol. 552, pp. 514-22, https://doi.org/10.1016/ j.msea.2012.05.080.

33. P. Mallick, N.K. Tewary, S.K. Ghosh, and P.P. Chattopadhyay: Mater. Charact., 2018, https://doi.org/10.1016/j.matchar.2017. 09.027.

34. T. Suzuki, J. Kojima, K. Suzuki, T. Hashimito, and M. Ichihara: Acta Metall., 1977, vol. 25, pp. 1151-62, https://doi.org/10.1016/ 0001-6160(77)90202-4.

35. N. Nakada, H. Ito, Y. Matsuoka, T. Tsuchiyama, and S. Takaki: Acta Mater., 2010, vol. 58, pp. 895-903, https://doi.org/10.1016/ j.actamat.2009.10.004

36. I. Shakhova, V. Dudko, A. Belyakov, K. Tsuzaki, and R. Kaibyshev: Mater. Sci. Eng. A, 2012, vol. 545, pp. 176-86, https:// doi.org/10.1016/j.msea.2012.02.101.

37. S. Sabooni, F. Karimzadeh, M.H. Enayati, and A.H.W. Ngan: Mater. Sci. Eng. A, 2015, vol. 636, pp. 221-30, https://doi.org/ 10.1016/j.msea.2015.03.101

38. L. Bracke, K. Verbeken, L. Kestens, and J. Penning: Acta Mater., 2009, vol. 57, pp. 1512-24, https://doi.org/10.1016/j.actamat.2008. 11.036.

39. B. Roy, R. Kumar, and J. Das: Mater. Sci. Eng. A, 2015, vol. 631, pp. 241-47, https://doi.org/10.1016/j.msea.2015.02.050.

40. T.S. Wang, J.P. Peng, Y.W. Gao, F.C. Zhang, and T.F. Jing: Mater. Sci. Eng. A, 2005, vol. 407, pp. 84-88, https://doi.org/ 10.1016/j.msea.2005.06.022

41. M. Eskandari, A. Kermanpur, and A. Najafizadeh: Metall. Mater. Trans. A, 2009, vol. 40A, pp. 2241-49, https://doi.org/10.1007/ s11661-009-9916-z.

42. T.-H. Lee, C.-S. Oh, S.J. Kim, and S. Takaki: Acta Mater., 2007, vol. 55, pp. 3649-62, https://doi.org/10.1016/j.actamat.2007. 02.023 .

43. M. Klimova, S. Zherebtsov, N. Stepanov, G. Salishchev, and D.A. Molodov: Mater. Charact., 2017, vol. 132, pp. 20-30, https:// doi.org/10.1016/j.matchar.2017.07.043.

44. K.G. Farkhutdinov, R.G. Zaripova, E.E. Sinitsyna, Kh.Y. Mulyukov, and B.F. Abdullin: Met. Phys., 1991, vol. 13, pp. 51-57 (in Russian).

45. A.A. Tiamiyu, J.A. Szpunar, A.G. Odeshi, I. Oguocha, and M. Eskandari: Metall. Mater. Trans. A, 2017, vol. 48A, pp. 59906012, https://doi.org/10.1007/s11661-017-4361-x.

46. A. Stormvinter, G. Miyamoto, T. Furuhara, P. Hedstrom, and A. Borgenstam: Acta Mater., 2012, vol. 60, pp. 7265-74, https:// doi.org/10.1016/j.actamat.2012.09.046.

47. J. Hirsch and K. Lucke: Acta Metall., 1988, vol. 36, pp. 2863-82, https://doi.org/10.1016/0001-6160(88)90172-1.

48. N. Hansen and D.J. Jensen: Philos. Trans. R. Soc. Lond. A, 1999, vol. 357, pp. 1447-69, https://doi.org/10.1098/rsta.1999.0384.

49. H. Kitahara, R. Ueji, N. Tsuji, and Y. Minamino: Acta Mater., 2006, vol. 54, pp. 1279-88, https://doi.org/10.1016/j.actamat.2005. 11.001 .

50. H. Kitahara, R. Ueji, M. Ueda, N. Tsuji, and Y. Minamino: Mater. Charact., 2005, vol. 54, pp. 378-86, https://doi.org/ 10.1016/j.matchar.2004.12.015.

51. B. Sonderegger, S. Mitsche, and H. Cerjak: Mater. Charact., 2007, vol. 58, pp. 874-82, https://doi.org/10.1016/j.matchar.2006.08.014. 